\title{
MANAJEMEN PROYEK SI
}

\section{Sistem Informasi Manajemen pada PT. POS \\ Indonesia}

LIA AULINA

165100113

Fakultas Komputer

liaaulina.student@umitra.ac.id

\begin{abstract}
suatu sistem, metodologi, strategi, perangkat lunak(software) dan aplikasi berbasis web yang mampu membantu sebuah perusahaan untuk mengelola hubungannya dengan para pemasok.Software EAI memungkinkan para pemakai membuat model berbagaiproses bisnis yang dilibatkan dalam interaksi yang harus terjadi antar aplikasi bisnis. EAI juga menyediakan middleware yang melakukan konversi dan koordinasi data, komunikasi aplikasi dan layanan pesan, serta akses ke berbagai interface aplikasi yang terlibat. Jadi, software EAI dapat mengintegrasikanberbagai kelompok aplikasi perusahaan dengan memungkinkan user bertukar data sesuai dengan peraturan dari model PT. Pos Indonesia (Persero) memanfaatkan sistem ERP ini pada operasi,jasa dan distribusi, dengan mempertimbangkan pengoprasian perusahaan pada proses internal melalui manajemen sumber daya manusia perusahaan, akuntansi, keuangan, logistik dan distribusi secara tepat waktu
\end{abstract}

Kata Kunci :system informasi manajemen pada PT.POS INDONESI 


\section{A. PENDAHULUAN}

Kemajuan teknologi telah diterapkan perusahaan untuk melakukan praktek baru pemasaran dan bisnis. Internet, sebagai bagian dari itu, secara dramatis mengubah bentuk pasar dan bisnis. Pola kehidupan secara bertahap berubah sejak penemuan teknologi internet.Internet merupakan sebuah koneksi global dari ribuan jaringan yang dikelola secara bebas (Budi Sutedjo, 2001:2). Internet, sebagai bagian dari kemajuan teknologi, secara dramatis telah membentuk ulang pasar dan bisnis. Konsumen di seluruh dunia ter-exposed akan cara hidup dan konsumsi baru dan menginginkan banyak dari hal-hal yang dilihatnya. Pola kehidupan berangsur-angsur mengalami perubahan sejak tercipta teknologi internet. Bisnis pun mulai mengadopsi internet sehingga mendukung terciptanya sistem. Banyak perusahaan di Indonesia sekarang dituntut untuk mempersiapkan diri dengan berbagai perangkat e-business sebagai bagian baru dari pola interaksinya dengan pelanggan, pemasok, dan karyawan. Salah satunya adalah PT. Pos Indonesia (Persero), sebagai perusahaan jasa pengiriman ternama di Indonesia. Perkembangan teknologi khususnya ICT (Information, Communication,Technology) yang demikian pesat, menjadi suatu ancaman sekaligus opportunity business bagi Pos saat ini dan di masa depan.

Bisnis Pos yang harus dilengkapi dengan bisnis berbasis ICT (Information, Communication, Technology) untuk memperkuat dan mempertahankan eksistensiPos.

E-Business merupakan salah satu bisnis dengan prospek besar dan Pos telah memiliki kompetensi di bidang ini, khususnya untuk me-leverage bisnis inti dan menciptakan peluang bisnis baru. 


\section{B. PEMBAHASAN} STUDI KASUS Pokok Bahasan

Aplikasi Utama $E$ -
business

Aplikasi-aplikasi utama $e$ business dan hubungannya satu sama laindiringkas dalam arsitektur perusahaan (Gambar 1). Aplikasi-aplikasi ini terintegrasi lintas fungsi perusahaan, contohnya seperti Enterprise ResourcePlanning (ERP), Manajemen Hubungan Pelanggan/ Customer

RelationshipManagement (CRM), dan Manajemen Rantai Pasokan/ Supply Chain Manajemen(SCM), Enterprise Aplication Integration (EAI), Transaction Processing Systems(TPS), Enterprise Collaboration System(ECS). Sistem ERP (Enterprise Resource Planning)

\section{Sistem informasi ERP} (Entreprise Resource Planning) merupakan suatusistem informasi yang diperuntukkan bagi perusahan manufaktur maupun jasa yang berperan mengintegrasikan dan mengotomasikan proses bisnis yang berhubungan dengan aspek operasi, produksi maupun distribusi di perusahaan bersangkutan

\section{Sistem Customer Relationship} Management (CRM)

Sistem CRM adalah suatu sistem, metodologi, strategi, perangkat lunak(software) dan aplikasi berbasis web yang mampu membantu sebuah perusahaan untuk mengelola hubungannya dengan para pelanggan. CRM terdiri atas tiga unsur pokok yaitu manusia, teknologi dan proses

\section{Supply Chain Management (SCM)}

Sistem SCM adalah suatu sistem, metodologi, strategi, perangkat lunak(software) dan aplikasi berbasis web yang mampu membantu sebuah perusahaan untuk mengelola hubungannya dengan para pemasok.

Integrasi Aplikasi Perusahaan/ Enterprise Aplication Integration (EAI) 
Software

EAI

memungkinkan para pemakai

membuat model berbagaiproses

bisnis yang dilibatkan dalam

interaksi yang harus terjadi antar

aplikasi bisnis. EAI juga

menyediakan middleware yang

melakukan konversi dan

koordinasi data, komunikasi

aplikasi dan layanan pesan, serta

akses ke berbagai interface aplikasi yang terlibat. Jadi,

software EAI dapat

mengintegrasikanberbagai

kelompok aplikasi perusahaan

dengan memungkinkan user

bertukar data sesuai dengan

peraturan dari model proses bisnis

yang dikembangkan oleh user.

Sistem Pemrosesan Transaksi/

Transaction Processing Systems (TPS)

TPS adalah sistem

informasi lintas fungsi yang memproses data dariterjadinya transaksi bisnis. Transaksi adalah berbagai kegiatan yang terjadi sebagai bagian dari aktivitas bisnis, seperti penjualan, pembelian, penyimpanan, penarikan, pengembalian dan pembayaran.

Sistem Kerjasama Perusahaan/

Enterprise Collaboration System (ECS)

ECS adalah sistem informasi lintas fungsi yang meningkatkan

komunikasi,koordinasi, dan kerjasama antar anggota tim bisnis dan kelompok kerja. Teknologi informasi, terutama teknologi Internet, memberikan berbagai alat untuk membantu perusahaan bekerjasama untuk mengomunikasikan berbagai ide, berbagi sumber daya dan mengkoordinasikan usaha kegiatan kerjasama sebagai anggota dari proses formal dan informal, tim proyek, dan kelompok kerja yang membentuk organisasi.

Subyek Informasi SIM

- PT.Pos Indonesia

SIM Yang Akan

Dikomunikasikan

Sistem Electronic Business PT

Pos Indonesia (Persero) 
E-Business merupakan salah satu bisnis dengan prospek besar dan Postelah memiliki kompetensi di bidang ini Aplikasi Enterprise Resource Planning (ERP)

PT. Pos Indonesia (Persero) memanfaatkan sistem ERP ini pada operasi,jasa dan distribusi, dengan mempertimbangkan pengoprasian perusahaan pada proses internal melalui manajemen sumber daya manusia perusahaan, akuntansi, keuangan, logistik dan distribusi secara tepat waktu.

ERP dibutuhkan perusahaan untuk bisa mendapatkan efisiensi, kecepatan, dan responsivitas yang dibutuhkan dalam mencapai keberhasilan di lingkungan bisnis yang dinamis saat ini.

Beberapa contoh aplikasi ERP pada PT. Pos Indonesia adalah untuk

mendukung:

IT (Information Technology)

Teknologi Informasi sangat penting dalam pelaksanaan kegiatan di karena adanya pengintegrasian berbagai proses dan entitas bisnis. Esensi dari pengintegrasian tersebut adalah melakukan share terhadap informasi yang dimiliki dan dihasilkan oleh berbagai pihak. Sebagai contoh adalahpengembangan jaringan sebagai alatpenunjang kinerja dari produk-produk EBusiness. Hal penting yang harus diperhatikan dalam pemilihan IT adalah scaleable solution \& open system, ini diperlukan agar sistem setiap saat dapat disesuaikan dengan kebutuhan. Dalam hal keterkaitan dengan proses bisnis, maka ketepatan IT yang digunakan akan mendorong/menentukan proses bisnis yang excellent.

\section{Business Process / Proses Bisnis}

Proses bisnis merupakan nilai pembeda (distinction) yang menciptakankeunggulan bersaing. Proses bisnis dalam E-Business sangat kental diwarnai oleh IT untuk menghasilkan mutu layanan yang akurat dan excellent. Sebuah proses bisnis yang baik, tentunya selain didukung dengan IT juga 
harus didukung oleh SDM yang berkompeten dan equipment yang sesuai dengan proses bisnis yang bertalian. Peran SDM tidak saja ditentukan oleh kemampuan teknis semata melainkan juga perilaku yang mencerminkan kerja keras, mandiri, jujur dan teamwork oriented.

Perfomance Standard / Standar Kinerja

Untuk dapat masuk dan bertahan dalam suatu bisnis minimal harus memiliki standar output yang sama dengan dengan standar yang berlaku umum di industri. Beberapa performance standard yang berlaku umum tidak terlepas dari faktor-faktor accuracy, speed, efficiency, dan flexibility.

Targeting

Arahan penggunaan pasar diarahkan berasarkan STP :

\section{Segmentasi}

Pembagian segmentasi dilakukan

berdasarkan lingkup bisnis serta

sumber daya

yang ada di lingkup bisnis PT.

Pos Indonesia :

- Lingkup Nasional
- Lingkup UPT

- Lingkup Wilpos

\section{Targeting}

Targeting pembagian bisnis mengarah pada lingkup arahan target yang potensial.

- Target para pelaku Bisnis

Bagi para pelaku bisnis mengarah pada private sector yaitu sektor swasta dan bisnis yang berorientasi pada profit.

\section{- Target Government}

Untuk target lingkup pemerintah target mengarah pada lembaga pemerintahan, serta mengarah pada instansi pemerintahan. Untuk yang lain target juga terfokus pada perusahaan Nirlaba.

- Individu

Arahan tertarget pada perseorangan seperti constumer individu serta para pengguna teknologi informasi seperti ICT (Information, Communication, Technology).

Aplikasi Customer Relationship Management (CRM)

PT. Pos Indonesia (Persero) memanfaatkan sistem 
CRM secara cukup intensif.

Antara lain pemanfaatannya adalah untuk mengelola programprogramdibawah ini:

Program e-fila.com. Khususnya dalam forum filateli. Selainmenguntungkan pelanggan, program ini juga menguntungkan PT. Pos Indonesia (Persero), karena dengan demikian dapat mengetahui perilaku pelanggan, melakukan perbaikan berdasarkan masukan dari pelanggan, merespon permintaan atau keluhan pelanggan dengan cepat dan terarah.

Program Kontak Kami (Gambar 4), yakni bagi pelanggan yang inginmenyampaikan komentar, kritik, saran, pertanyaan atau pengaduan kiriman, kepada pihak perusahaan.

\section{Aplikasi Supply Chain} Management (SCM)

PT. Pos saat ini memiliki outlet belanja produk-produk lengkap khasIndonesia secara online yang bernama Plaza Pos (Gambar 6) yang dapat diakses melalui alamat website www.plazapos.com. $\quad$ Serta memiliki program e-fila.com

PT. Pos Indonesia memanfaatkan sistem SCM untuk mengelola akunakunpemasoknya. Pemasokpemasok utama yang telah disyaratkan mempunyai pengetahuan memadai mengenai sitem informasi dan internetworking, serta mempunyai akses jaringan yang baik, dapat memantau data dan kegiatan pasokan mereka secara online dan realtime. Sedangkan pemasok konvensional yang masih menggunakan telepon atau cash and carry dikelola datanya oleh karyawan mitra utama, dimana transaksi dilakukan.

PT. Pos Indonesia melakukan sosialisasi mengenai program SCM inikepada para pemasok, dan menjelaskan berbagai nilai tambah (added value) antara lain membantu para pemasok mengatur transaksi, adanya prediksi kebutuhan PT. Pos Indonesia yang lebih akurat, 
dan diperluasnya jaringan kerja dari para pemasok.

Aplikasi Integrasi Perusahaan/

Enterprise

Application

Integration(EAI)

Aplikasi EAI pada PT. Pos

Indonesia salah satunya adalah pada layananPlaza Pos yakni pelanggan diminta untuk mengisi Member Area (Gambar 8), lalu melakukan submit. Dengan demikian, perusahaan mengetahui informasi pelanggan yang mengunjungi Plaza Pos.

Aplikasi Sistem Pemrosesan Transaksi/

Transaction

Processing Systems(TPS)

Sistem

Pemrosesan

Transaksi di PT. Pos Indonesia mendukung programPlaza Pos contohnya dalam akses pembayaran secara online, yakni aktivitas pemrosesan transaksi dibutuhkan untuk menangkap dan memproses data pelanggan, hingga transaksi pembayaran belanjanya melalui jaringan internet.
Aplikasi Sistem kerjasama

Perusahaan/ Enterprise

CollaborationSystem (ECS)

\begin{tabular}{|c|c|c|}
\hline \multicolumn{2}{|c|}{ Sistem } & ker \\
\hline perusahaan & pada & PT. \\
\hline Indonesia & & \\
\hline alamhubuı & & \\
\hline
\end{tabular}

Kemitraan merupakan kebutuhan yang mendasar dalam aktivitas Probis E-Business, karena hampir tidak mungkin aktivitas bisnis dapat dijalankan tanpa kemitraan. Sebagai contoh dalam aktivitas LimitedCommunication

Technology Services (eCom) dimana dalam pelaksanaan diperlukan adanya beberapa kerjasama terhadap perusahaan yang menggunakan jaringan PTSN, CDMA, GSM maka mutlak diperlukan kemitraan dengan pihak perusahaan itu.

\section{KESIMPULAN}

Kesimpulan dari materi ini adalah

Sistem Electronic Business yang dirancang PT. Pos Indonesia (Persero)mampu meningkatkan praktek bisnis jasa dan pemasarannya secara global.Perangkat Electronic 


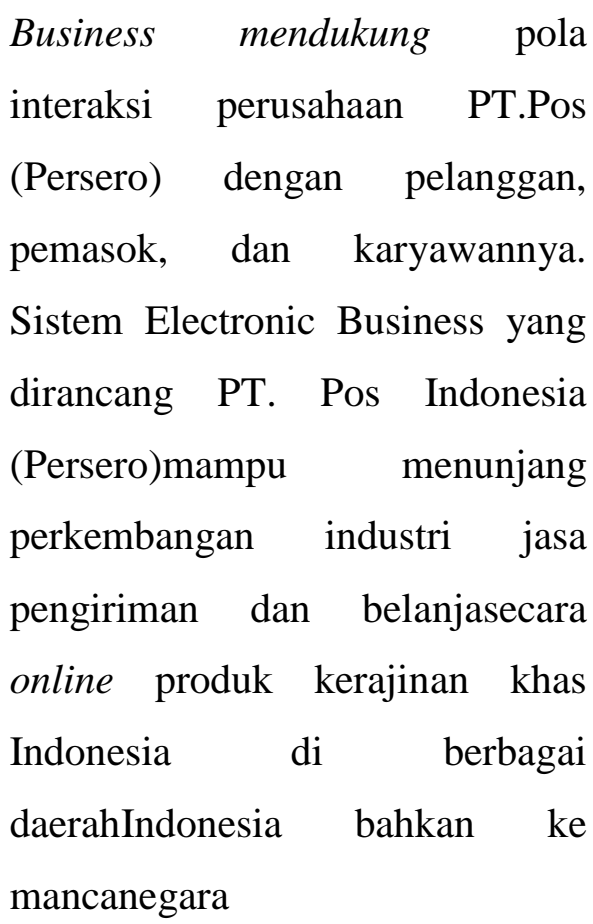

\section{DISKUSI}

Saya mendiskusikan tentang contoh ini dengan sangat baik Hasil diskusi dari materi ini adalah Sistem Electronic Business yang dirancang PT. Pos Indonesia (Persero)mampu meningkatkan praktek bisnis jasa dan pemasarannya secara global. Sistem Electronic Business yang dirancang PT. Pos Indonesia (Persero)mampu menunjang perkembangan industri jasa pengiriman dan belanjasecara online produk kerajinan khas Indonesia di berbagai daerahIndonesia bahkan ke mancanegara

\section{E. REFERENCE}

[1] O. M. Febriani and A. S. Putra, "Sistem Informasi Monitoring Inventori Barang Pada Balai Riset Standardisasi Industri Bandar Lampung," $J$. Inform., vol. 13, no. 1, pp. 90-98, 2014.

[2] A. S. Putra, "Paperplain: Execution Fundamental Create Application With Borland Delphi 7.0 University Of Mitra Indonesia," 2018.

[3] A. S. Putra, "2018 Artikel Struktur Data, Audit Dan Jaringan Komputer," 2018.

[4] A. S. Putra, "ALIAS MANAGER USED IN DATABASE DESKTOP STUDI CASE DB DEMOS."

[5] A. S. Putra, "COMPREHENSIVE SET OF PROFESSIONAL FOR DISTRIBUTE COMPUTING."

[6] A. S. Putra, "DATA ORIENTED

RECOGNITION IN BORLAND DELPHI 7.0."

[7] A. S. Putra, "EMBARCADERO

DELPHI XE 2 IN GPUPOWERED

FIREMONKEY APPLICATION."

[8] A. S. Putra, "HAK ATAS KEKAYAAN INTELEKTUAL DALAM DUNIA TEKNOLOGY 
BERBASIS REVOLUSI INDUSTRI 4.0."

[9]

A. S. Putra, "IMPLEMENTASI

PERATURAN

PERUNDANGAN UU. NO 31 TAHUN 2000 TENTANG DESAIN INDUSTRI BERBASIS

INFORMATION TECHNOLOGY."

[10] A. S. Putra, "IMPLEMENTATION OF PARADOX DBASE."

A. $\mathrm{S}$.

Putra, "IMPLEMENTATION OF TRADE SECRET CASE STUDY SAMSUNG MOBILE PHONE."

[12] A. S. Putra, "IMPLEMENTATION PATENT FOR APPLICATION WEB BASED CASE STUDI WWW. PUBLIKLAMPUNG. COM."

A. S. Putra, "IMPLEMENTATION SYSTEM FIRST TO INVENT IN DIGITALLY INDUSTRY."

[14] A. S. Putra, "MANUAL REPORT $\&$

INTEGRATED

DEVELOPMENT

ENVIRONMENT

BORLAND DELPHI 7.0."

[15] A. S. Putra, "PATENT AS RELEVAN SUPPORT RESEARCH."

[16] A. S. Putra, "PATENT FOR RESEARCH STUDY CASE OF APPLE. Inc."

[17] A. S. Putra, "PATENT
PROTECTION FOR APPLICATION

INVENT."

[18] A. S. Putra, "QUICK REPORT IN PROPERTY PROGRAMMING."

[19] A. S. Putra, "REVIEW CIRCUIT LAYOUT COMPONENT

REQUIREMENT ON ASUS NOTEBOOK."

[20] A. S. Putra, "REVIEW TRADEMARK PATENT FOR INDUSTRIAL TECHNOLOGY BASED 4.0."

[21] A. S. Putra, "TOOLBAR COMPONENT

PALLETTE IN OBJECT ORIENTED PROGRAMMING."

[22] A. S. Putra, "WORKING DIRECTORY SET FOR PARADOX 7."

[23] A. S. Putra, "ZQUERY CONNECTION IMPLEMENTED

PROGRAMMING STUDI CASE PT. BANK BCA Tbk."

[24] A. S. Putra, D. R. Aryanti, and I. Hartati, "Metode SAW (Simple Additive Weighting) sebagai Sistem Pendukung Keputusan Guru Berprestasi (Studi Kasus: SMK Global Surya)," in Prosiding Seminar Nasional Darmajaya, 2018, vol. 1, no. 1, pp. 85-97.

[25] A. S. Putra and O. M. Febriani, "Knowledge Management Online Application in PDAM 
Lampung Province," in Prosiding International conference on Information Technology and Business (ICITB), 2018, pp. 181187.

[26] A. S. Putra, O. M. Febriani, and B. Bachry, "Implementasi Genetic Fuzzy System Untuk Mengidentifikasi Hasil Curian Kendaraan Bermotor Di Polda Lampung," SIMADA (Jurnal Sist. Inf. dan Manaj. Basis Data), vol. 1, no. 1, pp. 21-30, 2018.

[27] A. S. Putra, H. Sukri, and K. Zuhri, "Sistem Monitoring Realtime Jaringan Irigasi Desa (JIDES) Dengan Konsep Jaringan Sensor Nirkabel," IJEIS (Indonesian J. Electron. Instrum. Syst., vol. 8, no. 2, pp. 221-232.

[28] D. P. Sari, O. M. Febriani, and A. S. Putra, "Perancangan Sistem Informasi SDM Berprestasi pada SD Global Surya," in Prosiding Seminar Nasional Darmajaya, 2018, vol. 1, no. 1, pp. 289-294. 